\title{
DEVELOPMENT OF AN ELECTROPLATING PROCESS FOR HIGH THROUGHPUT, HIGH YIELD MANUFACTURING OF MAGNETIC COMPONENTS
}

\author{
Steven D. Leith and Daniel T. Schwartz 1 \\ Department of Chemical Engineering, Box 351750 \\ University of Washington, Seattle, WA 98195
}

\author{
Keren Deng ${ }^{2}$ \\ MEMStek Products LLC. \\ Vancouver, WA 98661
}

\begin{abstract}
Geometrically complex NiFe components are deposited from a well characterized electrolyte using a custom designed plating apparatus. Structural and compositional features of plated parts are investigated using scanning electron microscopy (SEM) and energy dispersive $x$-ray spectroscopy (EDS). Results show that high rate, high yield electroplating of magnetic $\mathrm{NiFe}$ parts is possible through optimization of fundamental LIGA manufacturing principles.
\end{abstract}

\section{INTRODUCTION}

Many LIGA manufactured MEMS incorporate soft magnetic materials such as electroplated $\mathrm{NiFe}$ as mechanical microactuators $[1,2]$. The magnetic properties of electroplated $\mathrm{NiFe}$ are dictated by the composition and structure of the deposit which, in turn, are primarily determined by electrolyte mixing at the cathode surface and the applied current density during plating. Control of these processing variables on three length scales (i.e. workpiece, pattern and feature) is essential for successful plating of geometrically complex $\mathrm{NiFe}$ components with uniform magnetic properties. While much work has been devoted to optimization of throughmask plating of uniform NiFe deposits for use in magnetic data storage devices [2], this previous research has generally focused on plating through relatively thin photoresist masks $(<5 \mu \mathrm{m})$. With the increased interest in fabrication of much thicker, high aspect ratio magnetic components there exists a clear need for development of a manufacturing process for these types of materials. In this study, we report on the development and continual optimization of a high rate, efficient LIGA manufacturing process for fabrication of soft magnetic NiFe components. To achieve this goal, we have addressed three fundamental issues : I. Formulation and characterization of a $\mathrm{NiFe}$ plating bath; 2. Design and fabrication of a wafer-scale plating apparatus and 3. Design and fabrication of a well conceived PMMA pattern.

To assess and optimize the LIGA manufacturing process, NiFe microgears $\sim 200 \mu \mathrm{m}$ thick and $1200 \mu \mathrm{m}$ in diameter were galvanostatically plated onto a $\mathrm{Si} / \mathrm{Ti} / \mathrm{Cu}$ substrate through a patterned PMMA mask using a custom designed plating device developed in our lab. These microgear components serve as a

1. Author to whom correspondence should be addressed.

2. Current Address : CMRC, Semiconductor Research and Development,

Texas Instruments Incorporated, PO 655012, MS 921, Dallas, TX 75265 process test bed for proprietary magnetic actuator designs. Growth and composition uniformity within individual parts and across the wafer were studied using scanning electron microscopy (SEM) in conjunction with energy dispersive $x$-ray spectroscopy (EDS). Results from the composition and deposit growth analysis are used to probe the effects of local mixing and current distribution during plating and to investigate effects of process modifications. Based on our studies, a LIGA manufacturing process has been developed capable of plating NiFe components at least $200 \mu \mathrm{m}$ thick at rates exceeding $50 \mu \mathrm{m} / \mathrm{hr}$ with minimal yield loss due to deposit defects.

\section{EXPERIMENTAL DETAILS}

A nickel sulfamate/iron chloride plating bath capable of high rate $\mathrm{NiFe}$ plating was developed to operate at room temperature and $\mathrm{pH}$ $=3.00$ [3]. The bath was comprised of nickel and iron salts ( $\mathrm{Ni}: \mathrm{Fe}$ molar ratio $=20: 1)$, boric acid, sodium saccharin, sodium dodecyl

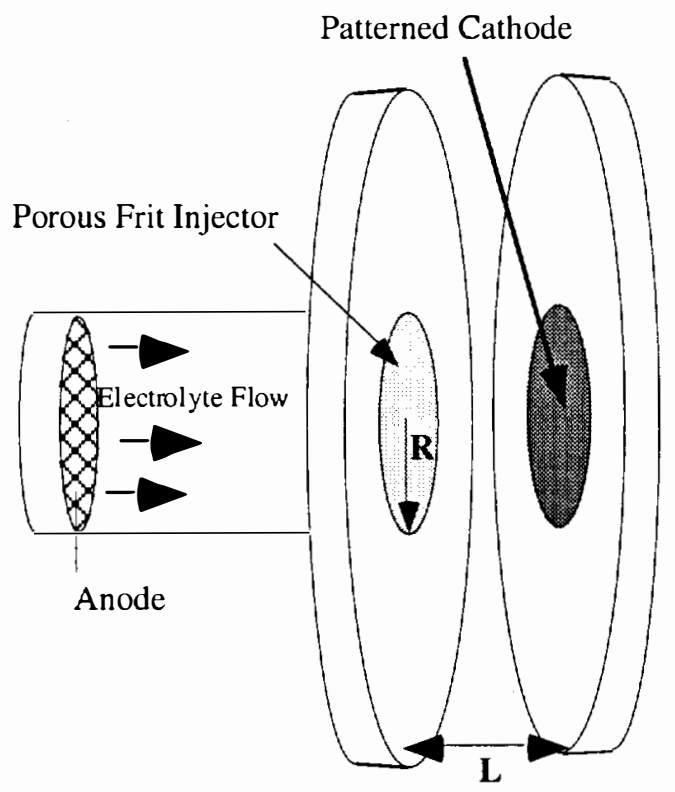

Figure 1. Schematic representation of the electroplating device. Operation with $L 2 R<1$ results in uniform convective mass transfer to and a uniform current distribution on the patterned cathode. 
sulfate and ascorbic acid. To determine the effects of electrolyte agitation and applied current density on alloy composition, NiFe films were electroplated onto a platinum rotating ring-disk electrode using a range of current densities and electrolyte mixing rates. Composition of the resulting deposits was determined using potentiostatic stripping voltammetry, a well known electroanalytic technique commonly used to determine the composition of electroplated alloys [4]. Relationships between electrolyte agitation rate, applied current density and deposit composition for the plating bath were determined for alloys plated at current densities ranging from -20 to $-100 \mathrm{~mA} / \mathrm{cm}^{2}$ and convective mass transfer coefficients ranging from 0.0015 to $0.013 \mathrm{~cm} / \mathrm{s}$ (i.e. from weak to very strong agitation).

A wafer-scale electroplating apparatus was fabricated based on the design of the uniform injection cell (UIC) and is shown schematically in Fig. $1[\mathbf{5 , 6}$. Proper operation of the UIC ensures uniform current distribution and electrolyte mixing at the workpiece length scale. NiFe microgears were electrodeposited from the nickel sulfamate/iron chloride plating bath onto a $\mathrm{Si} / \mathrm{Ti} / \mathrm{Cu}$ substrate through a patterned PMMA mask. To minimize the effects of current crowding at the edges of the patterned features, PMMA masks were designed such that individual patterned parts were closely packed [7]. A typical masked pattern measured $1.1 \times 1.6 \mathrm{~cm}$ and contained nearly 150 individual microgear parts. Plating gears to a thickness in excess of $200 \mu \mathrm{m}$ typically required between four and seven hours, depending on the current density used. After plating, the microgears were first planarized (while still confined within the mask) and then the PMMA was removed from the wafer. While still attached to the wafer, structural and compositional features of the plated microgears were studied using SEM and EDS.

\section{RESULTS AND DISCUSSION}

Figure 2 illustrates the relationships between plating current density (j), electrolyte mixing strength $(k)$ and deposit composition $\left(\mathrm{X}_{\mathrm{Fe}}\right)$ as determined from characterization of the plating bath. The

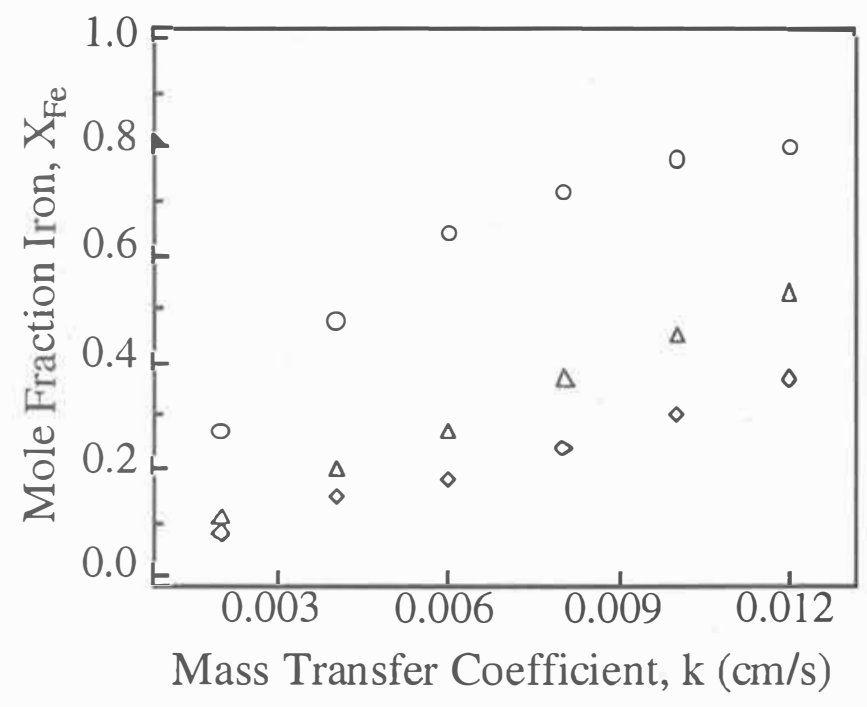

Figure 2. Effect of electrolyte mixing strength on the composition of NiFe electroplated at $-20(O),-60(\Delta)$ and $-100(\diamond) \mathrm{mA} / \mathrm{cm}^{2}$. Plating at high current densities andor with weak electrolyte mixing (i.e. small $k$ ) produces deposits with a high nickel concentration. figure shows that deposit composition is quite sensitive to variations in applied current density and electrolyte agitation. These data illustrate that through proper control of $j$ and $k$, engineered $\mathrm{NiFe}$ alloys of various compositions can be electroplated from the bath. Additionally, the figure shows that there are a number of different sets of plating conditions that can be employed to deposit any one desired alloy composition. For example, to deposit an alloy that is $28 \mathrm{~mol} \% \mathrm{Fe}$, one can electroplate at either $-20,-60$ or $-100 \mathrm{~mA} / \mathrm{cm}^{2}$, as long as adequate and well controlled electrolyte mixing is provided. While the results in Fig. 2 were determined using an unmasked, planar electrode, the same $\mathrm{X}_{\mathrm{Fe}}(\mathrm{j}, \mathrm{k})$ relationships are applicable to plating composition controlled, 3-dimensional MEMS components.

Figure 3 is an SEM micrograph showing electroplated permalloy (nominally $\mathrm{Ni}_{81} \mathrm{Fe}_{19}$ ) microgears $240 \mu \mathrm{m}$ thick and $1200 \mu \mathrm{m}$ in diameter before release from the wafer. Microgears shown in this figure were plated at $-60 \mathrm{~mA} / \mathrm{cm}^{2}$, corresponding to a deposit growth rate of $c a .65 \mu \mathrm{m} / \mathrm{hr}$. In many gears plated using an early

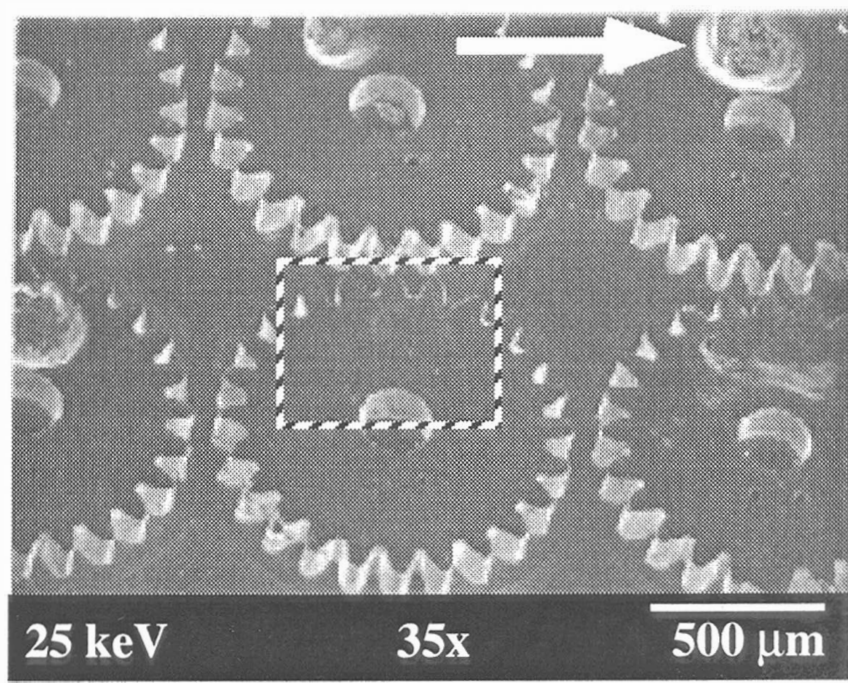

Figure 3. Scanning electron micrograph of electroplated permalloy microgears before release from the SiTi/Cu substrate. A plating rate of $65 \mu \mathrm{m} / \mathrm{hr}$ has been achieved using the plating apparatus shown in Fig. 1. The arrow points to a pit defect caused by gas evolution and entrapment during plating.

version of the UIC, gas evolution and entrapment resulted in creation of pit defects as indicated by the arrow in Fig. 3. This gas entrapment led to poor product yield in initial studies. Subsequent UIC design modifications have all but eliminated the problem and part yields are now close to $90 \%$.

Even though the UIC provides uniform mixing and current distribution at the workpiece, composition uniformity in plated microgears is affected by non-uniformities in electrolyte mixing and current density on the feature length scale. Figure 4 is an EDS composition map of a typical plated microgear in which dark shading represents relatively higher concentration of nickel. The figure shows subtle composition variation across the entire gear. Since current crowding at the tip of the gear teeth and near the hub of the gear results in relatively higher local current densities in these areas, such non-uniformity should lead to an overall higher (and roughly uniform) nickel concentration in these regions, as can be deduced from Fig. 2. However, it appears that local variations in electrolyte agitation within the gear (in the form of strong eddy mixing) results in bands of low nickel concentration as illustrated 


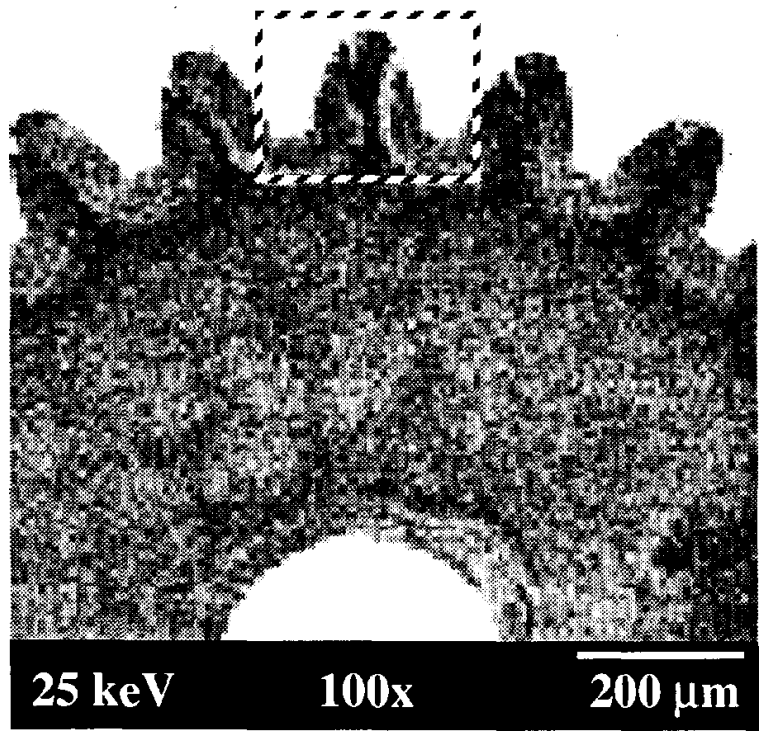

Figure 4. Composition map of the microgear shown in the boxed region of Fig. 3. Darker shading represents areas of relatively higher nickel concentrations. The map was created using energy dispersive $x$-ray spectroscopy.

by the light regions in Figs. 4 and 5 . To minimize compositionvariation within plated gears, we have modified the UIC to improve current density uniformity at the pattern scale and are currently developing a plating bath that is less sensitive to the electrolyte agitation conditions.

\section{CONCLUSIONS}

By addressing and optimizing the fundamental aspects of LIGA manufacturing, we have made significant progress toward development of an electroplating process for high throughput, high yield manufacturing of MEMS magnetic components. Through careful formulation and characterization of a plating bath and the design and fabrication of a wafer scale plating device, we have realized a 10 -fold increase in $\mathrm{NiFe}$ part throughput. Current studies are focusing on minimization of composition variation within plated parts through the systematic investigation of local current distribution and electrolyte mixing characteristics on the feature length scale.

\section{ACKNOWLEDGMENTS}

Support for this research was provided by MEMStek Products, the Washington Technology Center, and the National Science Foundation through a Young Investigator A ward to D.T. S..

\section{REFERENCES}

1. Tabat, N., Klein, J. and Guckel, H., "Single Flux-Path Bidirectional Linear Actuators", Transducers 97 Technical Digest, Vol. 2, pp. 789-792, 1997.

2. Romankiw, L.T., "A path : from electroplating through lithographic masks in electronics to LIGA in MEMS", Electrochim. Acta, Vol. 42, pp. 2985-3005, 1997.

3. Leith, S.D. and Schwartz, D.T., "Electrodeposition of NiFe Thin Films from a Sulfamate/Chloride Bath", Electrochim. Acta, submitted April, 1998.

4. Andricacos, P.C., Arana, C., Tabib, J., Dukovic, J. and Romankiw, L.T., "Electrodeposition of Nickel-Iron Alloys I. Effect of Agitation", J. Electrochem. Soc., Vol. 136, pp. 13361340, 1989.

5. Medina, J.A. and Schwartz, D.T., "Steady-State Characterization of the Uniform-Injection Cell I. Theoretical Analysis", $J$. Electrochem. Soc., Vol. 142, pp. 451-456, 1995.

6. Medina, J.A., Sexton, D.L. and Schwartz, D.T., "Steady-State Characterization of the Uniform-Injection Cell II. Experimental Analysis", J. Electrochem. Soc., Vol. 142, pp. 457-462, 1995.

7. DeBecker, B. and West, A.C., "Workpiece, Pattern, and Feature Scale Current Distributions", J. Electrochem. Soc., Vol. 143, pp. 486-492, 1996.

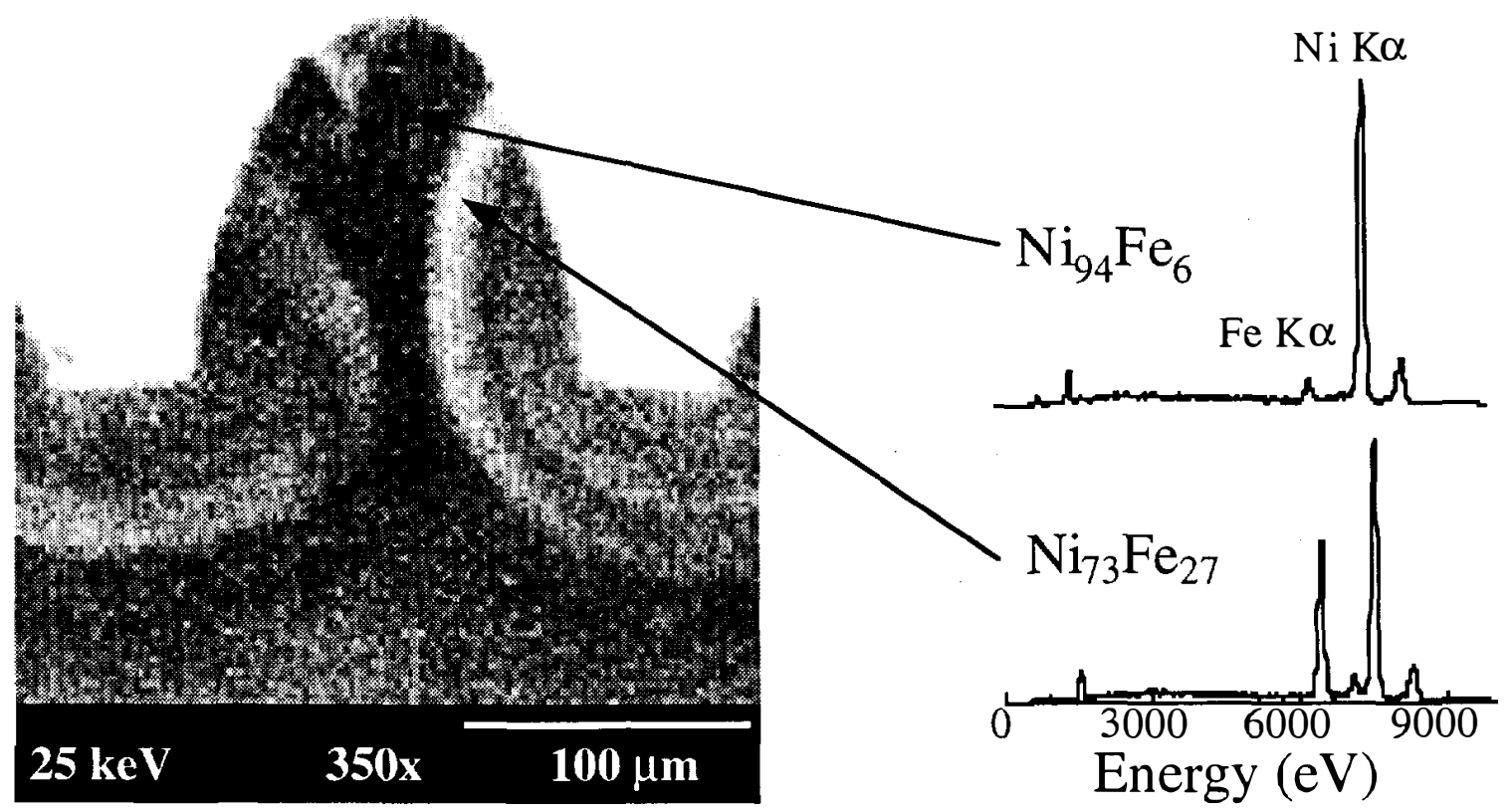

Figure 5. Composition map and x-ray energy spectra of the microgear tooth shown in the boxed area of Fig. 4. Local variation in composition results from feature-scale current density non-uniformities and flow effects within the pattern. 